\title{
Biopolíticas y Trabajo Sexual
}

\author{
Elles | Malgorzata Szumowska| 2011 \\ Lucía Busquier* \\ Escuela de Historia, Facultad de Filosofía y Humanidades, \\ Universidad Nacional de Córdoba
}

Recibido: 17 de mayo 2016; aprobado: 19 de junio 2016

\begin{abstract}
Resumen
Hace más de un siglo que la sociedad, el movimiento de mujeres y las organizaciones feministas, se encuentran atravesados por un debate que aun hoy sigue latente y sin resolverse: la prostitución, ¿es o no es un trabajo? Y en el caso de serlo, ¿cómo debería ser implementado, regulado y ejercido? A partir de este debate, nos proponemos analizar la película Elles de la directora Malgorzata Szumowska donde Anne, una periodista de la revista Elle, debe realizar entrevistas a estudiantes que eligen como su sustento económico el trabajo sexual. Para ello, intentaremos realizar un entrecruzamiento entre las definiciones de biopolítica y sexo que nos ofrece Michel Foucault, vinculándolo a la posición que la sociedad y el Estado asumen actualmente ante el trabajo sexual. Dicho film nos permitirá poner al descubierto ciertas tensiones y discursos que atraviesan a nuestras sociedades combinando prejuicios religiosos, morales e higienistas que tienen como única consecuencia la discriminación, estigmatización y persecución de quienes ejercen el comercio sexual.
\end{abstract}

Palabras clave: Trabajo Sexual | Prostitución | Biopolítica | Cuerpos

Biopolitics and Sex Work

Abstract

For more than a century the society, the women's movement and the feminist organizations are crossed by a debate which is still latent and unresolved: the prostitution, is or is not a job? And in the case of being so, how should it be implemented, regulated and exercised? From this discussion, we analyze the film Elles from the director Malgorzata Szumowska. In this film, Anne, a journalist from the magazine Elle, should make interviews to students who choose the sex work as financial support. To do this, we try to make a crossover between the definitions of biopolitics and sex that offers Michel Foucault, linking it to the position that society and the state currently assumed to sex work. This film will allow us to uncover some tension and discourses that cross our societies combining religious, moral prejudices and hygienists have the sole effect of discrimination, stigmatization and persecution of those who exercise the sex trade.

Keywords: Sexual work | Prostitution | Biopolitics | Bodies

\section{Trabajo Sexual o Prostitución: aproximaciones al debate}

Hace más de un siglo que la sociedad, el movimiento de mujeres y las organizaciones feministas, se encuentran atravesados por un debate que aun hoy sigue latente y sin resolverse: la prostitución ${ }^{1}$, ¿es o no es un trabajo? Y en el caso de serlo, ¿cómo debería ser implementado, regulado y ejercido?

Comúnmente se define al comercio sexual como el trabajo más antiguo del mundo. Los primeros registros sobre algún tipo de intercambio sexual por dinero $\mathrm{u}$ otros bienes datan del siglo XVIII a.C. en la Meso- potamia antigua. Durante la Grecia Clásica y el Imperio Romano, el trabajo sexual se convirtió en una actividad habitual entre los/las ciudadanos/as. Actualmente, cuando hablamos de trabajo sexual, nos referimos a un intercambio comercial donde una de las partes ofrece un servicio sexual a cambio de una retribución que puede ser económica o en otros bienes de intercambio. En algunos Estados está legalizado y regulado, mientras que en otros existen fuertes penalizaciones que no sólo castigan y persiguen a los/las clientes y proxenetas, sino también a quienes ejercen dicha actividad.

Dentro de este debate, podemos identificar dos grandes posiciones. Por un lado, se ubican los/las que con-

lu.busquier@hotmail.com 
sideran que el trabajo sexual debe ser reconocido como tal, permitiendo la sindicalización de dichas/os trabajadoras/os, así como también la obtención de derechos laborales y un reconocimiento por parte del Estado como una actividad legal. Por el otro, encontramos a las posiciones abolicionistas y probibicionistas que sostienen que dicha práctica es una forma de explotación sexual hacia las mujeres y por lo tanto debe ser abolida. Aunque muchas veces esto termina resultando en la persecución y criminalización de las/los trabajadoras/es. Cabe aclarar que en cada una de estas posturas pueden encontrarse diversas estrategias con las que se intenta llevar a cabo una u otra alternativa ${ }^{2}$.

\section{La película Elles y su aporte al debate}

En el film Elles (Francia, Polonia y Alemania, 2011) la directora Malgorzata Szumowska intenta poner en tensión algunos de los discursos comúnmente emitidos sobre el trabajo sexual.

Anne (Juliette Binoche), una periodista de la revista Elle, debe combinar sus tareas laborales con las exigencias cotidianas de una madre de dos hijos, esposa y ama de casa, lo que le genera gran cantidad de incomodidades y contradicciones que se muestran de manera sutil pero explícita a lo largo de toda la película.

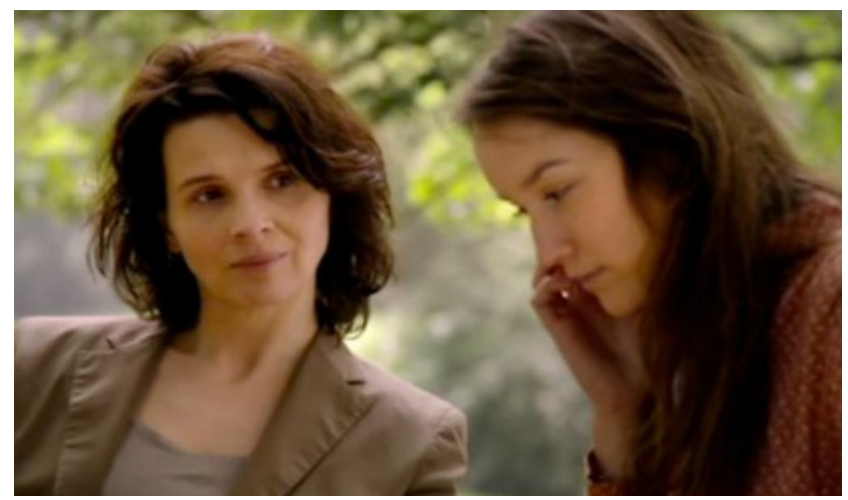

Anne se sumerge en la tarea de redactar un artículo para esta revista sobre el trabajo sexual ejercido por estudiantes universitarias. A partir de allí, la periodista desarrolla una serie de charlas y encuentros con algunas estudiantes universitarias que elijen el trabajo sexual como su principal fuente de ingresos. Las dos personas entrevistadas que muestra el film corresponden a dos realidades socioeconómicas diferentes: una de ellas es Charlotte (Anaïs Demoustier), hija de una familia clase media-alta, que decide empezar a trabajar en esta actividad aduciendo que puede obtener mayores ganancias que con cualquier otro trabajo, sin exigirle demasiadas horas al día. La otra entrevistada es Alicja (Joanna Kulig), una estudiante inmigrante de Polonia que comienza a ofrecer servicios sexuales para solventar sus gastos cotidianos, como por ejemplo, el alquiler de su departamento.

La elección de esos dos ejemplos por la realizadora de la película, apunta a poner en tensión la idea generalizada de que las trabajadoras sexuales se ven forzadas a recurrir al comercio sexual ante una situación extrema y como última alternativa. Por el contrario, la película más bien sugiere que los servicios sexuales pueden ofrecerse como un trabajo más ante una necesidad o deseo concreto, ya sea un nivel de vida socioeconómico más elevado al que ya se tiene o solventar los gastos económicos requeridos para acceder a una educación universitaria.

A medida que Anne comienza a desarrollar las entrevistas y a encontrarse de manera más íntima con las estudiantes y trabajadoras sexuales, sus prejuicios sobre el comercio sexual comienzan a desaparecer generando cierta empatía con ellas. Al mismo tiempo, esta situación impulsa nuevas sensaciones en la periodista quien ve tambalear su rol como esposa, madre y profesional. Comienza a implicarse en su propia insatisfacción y malestar respecto de su trabajo y del lugar que ella tiene para su marido e hijos. Las conversaciones íntimas que mantiene con sus entrevistadas se tornan para ella un refugio y espacio de reflexión sobre lo propio.

A su vez, una de las ideas que atraviesa el discurso de las trabajadoras sexuales en esta película y de manera transversal, es el tipo de clientes con los que realizan sus encuentros sexuales. En el film, aparece de manera permanente la idea de que los clientes son "esposos que están aburridos”, como lo dice explícitamente una de las entrevistadas en una de las escenas, ya que los clientes que se muestran en la película son padres de familia, hombres entre 30 y 50 años, empresarios acomodados. La escena final de la película resume esta idea ya que en una cena donde participa la protagonista, su marido, el jefe de su marido y otros invitados/as, los personajes allí sentados se transforman en su fantasía en los clientes de las estudiantes entrevistadas. Este recurso de la directora pone de manifiesto los prejuicios morales que señalan a las trabajadoras sexuales como personas que "atentan contra el hogar y la familia”. Prejuicios que penetran en los entramados sociales y discursivos, convirtiendo al trabajo sexual en algo ilegal, clandestino e inmoral, haciendo recaer la responsabilidad en estas trabajadoras, y librando de culpas a los clientes. 
La realizadora, desde estaperspectiva, logra desmontar prejuicios. El juego de palabras que se produce entre el nombre de la revista para la que trabaja la protagonista (Elle - ella) y el nombre de la película (Elles-ellas), que en francés se pronuncian de la misma manera, deja entrever esta idea, de que a pesar de los prejuicios morales y religiosos que atraviesan al comercio sexual, quienes deciden ejercerlo son mujeres comunes, de todas las clases sociales, etnias y nacionalidades. Y, de la misma manera, quienes recurren a estos servicios son varones, mujeres y otras diversidades sexo-genéricas; adultos/ as, jóvenes y ancianos/as. Es decir, sin distinciones de géneros, edades, ni clases sociales.

\section{Biopolíticas, sexo y cuerpos}

En este último apartado recuperaremos algunos de los conceptos fundamentales de Michel Foucault que nos servirán para reflexionar sobre el planteo de este trabajo. En Defender la Sociedad, Foucault nos dice que la biopolítica tiene que ver con el control de los aspectos comunes de la vida como la natalidad, la mortalidad, la longevidad, etc. (Foucault, 2010: 3). Es por ello que el trabajo sexual corresponde un tema de agenda para los estados actuales, ya que, estas nuevas políticas de la era moderna de la que nos habla Foucault, se sustentan en dos líneas fundamentales. Por un lado, la disciplina, vigilancia y castigo al cuerpo individual a través de las instituciones y, por otro lado, el control y la regulación de la población y los procesos biológicos a través de mecanismos reguladores del Estado (Foucault, 2010: 7).

Es decir, los Estados que deciden penalizar o prohibir el ejercicio del trabajo sexual, aplican una vigilancia, disciplina y castigo específicos hacia los cuerpos de las trabajadoras sexuales aplicando penalizaciones puntuales a quienes ejercen el comercio sexual y, por otro lado, impulsan regulaciones a la población en su conjunto basándose en instituciones como el aparato represivo (policía, ejército, etc.), la medicina social y otras instituciones específicas como los hospitales y campañas de difusión de las enfermedades de transmisión sexual que comúnmente son vinculadas al trabajo sexual. Con todo esto, los estados se sustentan sobre una biopolítica para construir e intervenir sobre determinados cuerpos: las trabajadoras sexuales ${ }^{3}$.

Otra de las estrategias que los estados utilizan para ejercer el control sobre estos cuerpos es el de la medicina social que funciona como un elemento fundamental para la aplicación de ciertas leyes, regulaciones y campañas de difusión sobre las enfermedades venéreas, adjudicando un cuerpo contagioso, enfermo y peligroso para la sociedad a quienes ejercen el comercio sexual. Esta medicina social se aplica tanto sobre el cuerpo social, como sobre los cuerpos en particular, es decir, la medicina también es una estrategia biopolítica (Foucault, 1999: 363-384).

Por su parte, el sexo también juega un rol fundamental a la hora de analizar cómo se disciplinan los cuerpos. Foucault nos dice que el sexo depende, por un lado, de las disciplinas aplicadas al cuerpo, es decir, el adiestramiento, la intensificación y distribución de las fuerzas y las energías. Por otro lado, el sexo participa activamente en la regulación de las poblaciones: un micropoder sobre el cuerpo (Foucault, 2014: 138). Al mismo tiempo, de manera combinada y en simultáneo, se desarrollan medidas masivas e intervenciones hacia toda la población, al cuerpo social entero. Es por ello que el sexo se convierte en el acceso a la vida del cuerpo y a la vida de la especie, utilizando diversas regulaciones (Foucault, 2014: 138). Los cuerpos de las trabajadoras sexuales representan una amenaza a este orden y disciplinamiento ya que, por un lado, el comercio sexual atenta contra el ideal de familia burguesa monogámica encargada de reproducir la mano de obra para el desarrollo de la sociedad y, por otro lado, como dijimos anteriormente, quienes ejercen el intercambio sexual son consideradas como cuerpos enfermos y contagiosos, poniendo en riesgo la salud de toda la población.

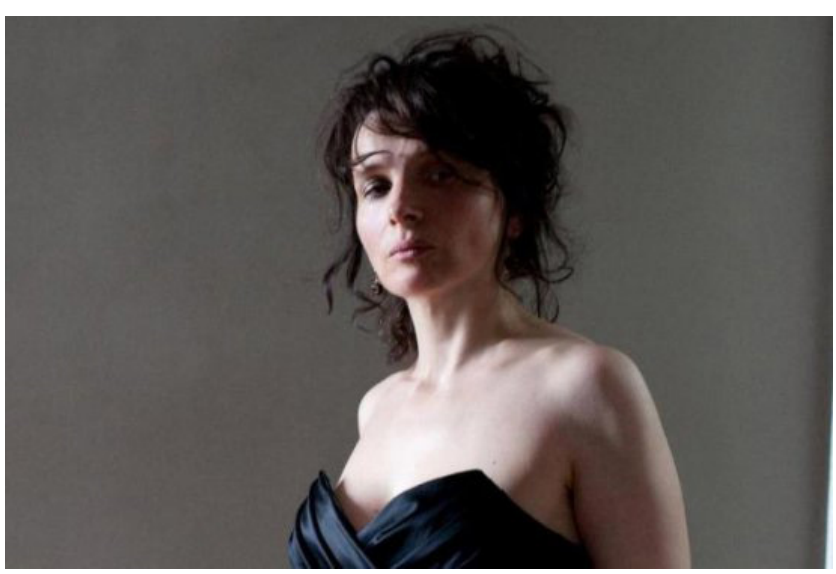

Considerando lo antedicho, el film Elles muestra, de alguna manera, la posición foucaultiana ya que, a partir de los diálogos entre las trabajadoras sexuales y la periodista, se expone la situación real en la que se encuentra el trabajo sexual en la actualidad, sin caer en juicios de valor ni moralismos. Aunque la película no hace referencia al Estado y sus biopolíticas hacia 
este tipo de trabajo y los cuerpos de quienes ejercen dicha actividad, contribuye a otras aristas del debate relacionadas con la percepción que tiene la sociedad sobre el comercio sexual. Además, de manera paralela, intenta cuestionar la vida cotidiana de una madre, mujer profesional, que se encuentra bajo las presiones de sus exigencias laborales y matrimoniales que no le permiten conectarse con sus gustos personales. Las entrevistas que la periodista realiza a ellas, las trabajadoras sexuales, vemos en el film, serán el puente que le permita sumergirse en un mundo paralelo, no demasiado diferente al que ella vive.

\section{Referencias}

Fassi, Marisa. “Discursos y leyes sobre prostitución/trabajo sexual”. José Morán Faúndes, María Sgró Ruata y Juan Marco Vaggione (eds.). Sexualidades, desigualdades y derechos: Reflexiones en torno a los derechos sexuales y reproductivos. Córdoba: Ciencia, Derecho y Sociedad. 2012, pp. 337-362.

Foucault, Michel. “Nacimiento de la medicina social”. Obras Esenciales, Vol. II: Estrategias de poder. España: Paidós. 1999, pp. 363-384.

Foucault, Michel. “Clase del 17 de marzo de 1976”. Defender la sociedad. Buenos Aires: Fondo de Cultura Económica. 2010.

Foucault, Michel. "Derecho de muerte y poder sobre la vida”. Historia de la Sexualidad, Vol. I: La Voluntad de Saber. México: Siglo XXI Editores. 2014, pp. 127-152.

Morcillo, Santiago y Justo Von Lurzer, Carolina. "Mujeres públicas y sexo clandestino. Ambigüedades en la normativa legal sobre prostitución en la Argentina”. Jones, Daniel; Figari, Carlos; Barrón López, Sara (Coord). La producción de la Sexualidad. Políticas y regulaciones sexuales en Argentina. Buenos Aires: Biblos. 2012, pp. 169-196.

Wijers, Marjan. "Delincuente, víctima, mal social o mujer trabajadora: perspectivas legales sobre la prostitución”. Raquel Osborne (ed.).Trabajador@s del sexo: Derechos, migraciones y tráfico en el siglo XXI. Barcelona: Ediciones Bellaterra. 2004, pp. $209-221$.

\footnotetext{
1 Debido a las implicancias políticas que actualmente recibe cada término, en este trabajo usaremos el de trabajo sexual y no el de prostitución, buscando fortalecer la idea de que dicha actividad debe ser reconocida como un trabajo.

2 Para más información sobre el debate se recomienda la lectura de: Fassi, 2012; Morcillo y Justo Von Lurzer, 2012 ; Wijers, 2004.

3 Cabe aclarar que en el universo del comercio sexual no sólo se incluye a las mujeres, sino también a hombres, transexuales, travestis, etc. pero para este trabajo en particular consideraremos sólo el trabajo sexual ejercido por mujeres.
} 